\title{
Resting Energy Expenditure in Neurofibromatosis Type 1: Indirect Calorimetry versus Predictive Equations
}

\author{
Marcio L.R. Souza*, Ann K. Jansen, Luiz O.C. Rodrigues, Darlene L.S. Vilela, Aline S. Martins, Juliana F. Souza, \\ Nilton A. Rezende \\ Federal University of Minas Gerais, Belo Horizonte - MG, Brazil
}

Article Info

\section{Article Notes}

Received: May 21, 2020

Accepted: June 19, 2020

\section{*Correspondence:}

Souza MLR, PhD, Rua dos Guajajaras, 1470 / 1702, Belo

Horizonte, MG, Brazil:

Email: marcionutricionista@yahoo.com.br.

${ }^{2} 2020$ Souza MLR. This article is distributed under the terms of the Creative Commons Attribution 4.0 International License.

\section{Keywords}

Neurofibromatosis type 1

Resting energy expenditure

Total energy expenditure

Nutritional status

Metabolism

Indirect calorimetry

\section{Abstract}

Increased resting metabolism, by indirect calorimetry (IC), has been observed in neurofibromatosis type 1 (NF1) patients as compared to in the unaffected population. As IC is not an easily available method, the present study aimed to measure resting energy expenditure (REE) in adults with NF1 by using $\mathrm{IC}$ and determine the most appropriate equation to estimate the predictive value of this variable in clinical practice. Twenty-six NF1 patients aged between 18 and 45 years underwent nutritional assessment, including weight, height, and body mass index. Body composition was measured by dual energy x-ray absorptiometry (DXA). RMR was measured by IC (mREE) and by eight different equations (pREE). Statistical analysis were carried out by Kolmogorov-Smirnov test, paired student's $t$ test, and Bland and Altman plots. The mean age was $34.3 \pm 6.1$ years. The mean mREE was $1633.9 \pm 471.1 \mathrm{kcal}$, and the PREE ranged from $1244.6 \pm 239.9 \mathrm{kcal}$ to $1519.9 \pm 271.1$. The best predictive REE equation for individuals with NF1 was the WHO equation (weight and height), given its small difference (although significant; $P=0.041$ ) from the values obtained using the gold standard, good median of adequacy (92.0\%), and high accuracy $(46.2 \%)$. This study showed that all the eight predictive equations underestimated REE in NF1 patients (with large differences and low accuracy when compared to a gold standard method). IC is the preferred way to avoid over or underestimation of REE in NF1 patients.

\section{Introduction}

Neurofibromatosis type 1 (NF1) is the most prevalent form of neurofibromatosis; it is a genetic disease caused by inherited or de novo mutations on chromosome 17, resulting in reduced neurofibromin synthesis, which subsequently reduces tumor suppression $^{\mathbf{1}}$. The diagnostic criteria for NF1 are established by the National Institute of Health (NIH) Consensus ${ }^{2}$. The most common clinical features of NF1 are café au lait spots, dermal neurofibromas, plexiform neurofibromas, axillary and/or inguinal freckling, Lisch nodules, and bone dysplasia. However, NF1 can also exhibit multisystemic involvement, including musculoskeletal, endocrine, cardiovascular, and central and peripheral neural systems, learning deficits, and speech disorders ${ }^{\mathbf{1 , 3 , 4 , 5}}$.

The first study ${ }^{6}$ of nutrient intake in NF1 patients was published in 2015 , and the authors observed that $71.7 \%$ of NF1 patients did not meet their energy needs. This study used the estimated energy requirements (EER) equation for dietary reference intake proposed by the Institute of Medicine, USA, which takes into account sex, weight, age, height, and physical activity level. One of the problems arising would be that this equation could overestimate the energy requirement in NF1, which has not yet been investigated ${ }^{6}$. Recently, 
Souza et al. ${ }^{7}$ showed an increased resting metabolism in NF1 patients compared to the non-NF1 group matched by age, sex, body mass index (BMI), and physical activity level.

Total energy expenditure (TEE) is an important component of nutritional assessment since it helps determine of the energy needs of an individual, thus contributing to improved treatment. "How much should we feed this patient?" The question sounds simple, but it is important that a patient's TEE in not under or overestimated ${ }^{8}$.

TEE is usually composed of three components: basal energy expenditure (BEE), thermal effect of food, also called diet-induced thermogenesis, and energy expenditure to support physical activity ${ }^{\mathbf{8}, 9}$. The BEE corresponds to energy expenditure related to basal metabolism and represents approximately $60-75 \%$ of the TEE in sedentary individuals. This parameter represents the energy expended by the body to maintain its vital functions, for example, cardiovascular and respiratory functions or thermoregulatory mechanisms in maintaining body temperature ${ }^{\mathbf{8 , 1 0}}$. However, this basal condition is difficult to evaluate in routine patient care. For this reason, resting energy expenditure (REE) is used since it is easier to measure than the BEE and presents a value with a very small difference from the basal value, ranging from $3 \%$ to $10 \%$. In addition, it can be measured with the subject at rest/ awake in a thermoneutral and comfortable environment ${ }^{8}$.

IC is the gold standard for REE evaluation, but due to high cost and time demand, predictive equations are widely used in clinical practice for patient care ${ }^{\mathbf{8 , 9 , 1 0}}$. Souza et al. ${ }^{7}$ investigated the usefulness of the IC method in NF1 patients; but at this moment, little is known about REE in this disease. Thus, the present study aimed to compare the values obtained from predictive REE equations and from IC to identify the best equation for NF1 patients.

\section{Methods}

\section{Sample}

The present cross-sectional study included NF1 patients aged $\geq 18$ years from a Brazilian neurofibromatosis outpatient reference center evaluated between March 2016 and July 2016, as per the methods proposed by Souza et al. ${ }^{7}$. This study was approved by the Ethics Committee of the Federal University of Minas Gerais (\#776.524CAAE: 03005812.6.0000.5149). All patients provided written informed consent. Patients with musculoskeletal limitations, use of medications that might compromise nutritional assessment, presence of diseases that required a specific diet, malignant lesions, hypothyroidism, or weight loss $>10 \%$ in the last 6 months were excluded. Additionally, men aged over 50 years and postmenopausal women suspected of osteoporosis were excluded because this study used dual energy x-ray absorptiometry (DXA).

\section{Data Collection}

The anthropometric measurements were recorded as per the protocol outlined by the World Health Organization (WHO) $)^{11,12}$. Weight was measured to the nearest $100 \mathrm{~g}$ using a digital scale (Filizola ${ }^{\circledR}$, Brazil), which was checked regularly before each investigation, and height was measured using a vertical stadiometer (Filizola ${ }^{\circledR}$, Brazil). Weight and height were used to calculate the BMI. The BMI categories used in this study were normal weight (BMI, 18.5-24.9 kg/m²), underweight (BMI $\left.<18.5 \mathrm{~kg} / \mathrm{m}^{2}\right)$, and overweight $\left(\mathrm{BMI} \geq 25.0 \mathrm{~kg} / \mathrm{m}^{2}\right)^{11,12}$. Body composition was measured by DXA, equipment Discovery W Hologic ${ }^{\circledR}$ (Bedford, MA, USA), version 3.3.0, where the entire body was scanned for 6 minutes as per the manufacturer's instructions. DXA is considered the gold standard method for body composition assessment as it measures fat, lean, and bone mass. Physical activity level was evaluated using the validated International Physical Activity Questionnaire (IPAQ) short version ${ }^{\mathbf{1 3}}$.

IC was used to evaluate the REE. A Quark RMR® opencircuit calorimeter (Cosmed $^{\circledR}$, Rome, Italy) was used for this analysis using the Canopy system. All individuals had fasted for at least 6 hours ${ }^{10,14}$. The tests were performed around 2:00 pm, with the patients having fasted from 8:00 am. The patients were instructed to refrain from consuming food, water, and other liquids. As part of the protocol, the patients were instructed to avoid performing physical activities for 24 hours before the test and to refrain from smoking and consuming caffeine or other stimulants 6 hours before the test $\mathrm{t}^{\mathbf{1 0}, 14}$.

The calorimeter was switched on for at least 15 minutes prior to calibration and heating and stabilization tests. All quality parameters recommended by the manufacturer were evaluated and confirmed before each exam. All the tests were performed in the same room, lasting between $14 \mathrm{~h}$ and $15 \mathrm{~h}$ overall, in a quiet environment, at the same temperature $\left(23-25^{\circ} \mathrm{C}\right)$. The patients lay in the supine position for at least 15 minutes prior to the start of the test. Oxygen consumption $\left(\mathrm{VO}_{2}\right)$ and carbon dioxide production $\left(\mathrm{VCO}_{2}\right)$ were continuously evaluated for approximately 20 minutes, with data recorded every 5 seconds. The first five minutes were disregarded to ensure adequate acclimatization, and the mean of the last 15 minutes was considered in the analysis. The patients were instructed not to talk or sleep during the evaluation as well as to avoid yawning, coughing, or being agitated ${ }^{\mathbf{1 0 , 1 4}}$.

The $\mathrm{VO}_{2}$ and $\mathrm{VCO}_{2}$ values provided by the equipment were used to calculate the REE according to the Weir equation ${ }^{15}$, without using the urinary nitrogen levels, usually taken from the equation, since they correspond to less than $4 \%$ of the actual energy expenditure and contribute to a small error of $1-2 \%$ in the calculation of energy expenditure ${ }^{\mathbf{1 4}}$. The REE values measured by the IC 
Table 1. Predictive REE equations selected for this study

\begin{tabular}{|c|c|}
\hline REFERENCE & EQUATION \\
\hline Harris-Benedict (1919) ${ }^{16}$ & $\begin{array}{l}\text { Male: } \mathrm{REE}=66.4730+13.7516 \times \mathrm{W}(\mathrm{kg})+5.0033 \times \mathrm{H}(\mathrm{cm})-6.7550 \times \mathrm{A}(\mathrm{y}) \\
\text { Female: } \mathrm{REE}=655.0955+9.5634 \times \mathrm{W}(\mathrm{kg})+1.8496 \times \mathrm{H}(\mathrm{cm})-4.6756 \times \mathrm{A}(\mathrm{y})\end{array}$ \\
\hline $\begin{array}{l}\text { WHO }(1985)^{17} \\
\text { Including only weight }\end{array}$ & $\begin{array}{l}\text { Age } 18-30 \text { (males) } \rightarrow \mathrm{REE}=15.3 \times \mathrm{W}(\mathrm{kg})+679 \\
\text { Age } 18-30 \text { (females) } \rightarrow \mathrm{REE}=14.7 \times \mathrm{W}(\mathrm{kg})+496 \\
\text { Age } 30-60 \text { (males) } \rightarrow \mathrm{REE}=11.6 \times \mathrm{W}(\mathrm{kg})+879 \\
\text { Age } 30-60 \text { (females) } \rightarrow \mathrm{REE}=8.7 \times \mathrm{W}(\mathrm{kg})+829\end{array}$ \\
\hline $\begin{array}{l}\text { WHO }(1985)^{17} \\
\text { Including weight and height }\end{array}$ & $\begin{array}{l}\text { Age } 18-30 \text { (males) } \rightarrow \text { REE }=15.4 \times \mathrm{W}(\mathrm{kg})-27 \times \mathrm{H}(\mathrm{m})+717 \\
\text { Age } 18-30 \text { (females) } \rightarrow \mathrm{REE}=13.3 \times \mathrm{W}(\mathrm{kg})+334 \times \mathrm{H}(\mathrm{m})+35 \\
\text { Age } 30-60 \text { (males) } \rightarrow \text { REE }=11.3 \times \mathrm{W}(\mathrm{kg})+16 \times \mathrm{H}(\mathrm{m})+901 \\
\text { Age } 30-60 \text { (females) } \rightarrow \text { REE }=8.7 \times \mathrm{W}(\mathrm{kg})-25 \times \mathrm{H}(\mathrm{m})+865\end{array}$ \\
\hline Schofield et al. $(1985)^{18}$ & $\begin{array}{l}\text { Age } 18-30 \text { (males) } \rightarrow \text { REE }=(0.063 \times \mathrm{W}(\mathrm{kg})+2.896) \times 239 \\
\text { Age } 18-30 \text { (females) } \rightarrow \text { REE }=(0.062 \times \mathrm{W}(\mathrm{kg})+2.036) \times 239 \\
\text { Age } 30-60 \text { (males) } \rightarrow \text { REE }=(0.048 \times \mathrm{W}(\mathrm{kg})+3.653) \times 239 \\
\text { Age } 30-60 \text { (females }) \rightarrow \text { REE }=(0.034 \times \mathrm{W}(\mathrm{kg})+3.538) \times 239\end{array}$ \\
\hline Henry \& Rees (1991) ${ }^{19}$ & $\begin{array}{l}\text { Age } 18-30 \text { (males) } \rightarrow \text { REE }=(0.056 \times \mathrm{W}(\mathrm{kg})+2.800) \times 239 \\
\text { Age } 18-30 \text { (females) } \rightarrow \mathrm{REE}=(0.048 \times \mathrm{W}(\mathrm{kg})+2.562) \times 239 \\
\text { Age } 30-60 \text { (males) } \rightarrow \mathrm{REE}=(0.046 \times \mathrm{W}(\mathrm{kg})+3.160) \times 239 \\
\text { Age } 30-60 \text { (females) } \rightarrow \mathrm{REE}=(0.048 \times \mathrm{W}(\mathrm{kg})+2.448) \times 239\end{array}$ \\
\hline Cunningham $(1980)^{20}$ & REE $=500+22 \times$ LBM $(\mathrm{kg})$ \\
\hline Cunningham $(1991)^{21}$ & $\mathrm{REE}=370+21.6 \times \mathrm{FFM}(\mathrm{kg})$ \\
\hline Mifflin-St. Jeor (1990) $)^{22}$ & $\begin{array}{l}\text { Male: } \mathrm{REE}=10 \times \mathrm{W}(\mathrm{kg})+6.25 \times \mathrm{H}(\mathrm{cm})-5 \times \mathrm{A}(\mathrm{y})+5 \\
\text { Female: } \mathrm{REE}=10 \times \mathrm{W}(\mathrm{kg})+6.25 \times \mathrm{H}(\mathrm{cm})-5 \times \mathrm{A}(\mathrm{y})-161\end{array}$ \\
\hline
\end{tabular}

Note: REE: resting energy expenditure; $\mathrm{W}$ : weight; $\mathrm{H}$ : height; $\mathrm{A}$ : age; kg: kilograms; $\mathrm{y}$ : years; $\mathrm{m}$ : meters; cm: centimeters; FFM: fat-free mass; LBM: lean body mass; WHO: World Health Organization

were termed as mREE and compared with values obtained from eight predictive equations ( $\mathrm{pREE}$ ) described in Table 1.

\section{Statistical Analyses}

All statistical analyses were conducted using the Statistical Package for Social Sciences (SPSS ${ }^{\circledR}$ ) version 19.0 for Windows (SPSS Inc., Chicago, IL, USA). The Kolmogorov-Smirnov test was used to evaluate normality and determine the appropriate statistical test. Qualitative variables were described using absolute and relative (percentage) frequencies. Quantitative variables with normal distribution were expressed as mean and standard deviation and compared using the paired student's $t$-test. Quantitative variables that were not normally distributed were presented as median and interquartile range (IQR) or minimum and maximum and compared using the nonparametric Wilcoxon test. The Bland and Altman method was used to verify the concordance between the values predicted by the equations and by the gold standard method. $P$-values $<0.05$ were considered statistically significant.

\section{Results}

Twenty-six patients aged 18-45 years were included in this study; 14 (53.8\%) were men. The mean age was 34.31 \pm 6.05 years, and there was no age difference between the men and women $(P=0.980)$. Anthropometric and body composition data are shown in Table 2. As per the BMI
Table 2. Demographic, anthropometric, and body composition data of the sample

\begin{tabular}{|l|c|}
\hline \multicolumn{1}{|c|}{ Parameters } & NF1 Patients $(\mathbf{n = 2 6 )}$ \\
\cline { 2 - 2 } & Mean (SD) \\
\hline Age (years) & $34.31(6.05)$ \\
\hline Weight $(\mathrm{kg})$ & $62.54(16.99)$ \\
\hline Height $(\mathrm{m})$ & $1.61(0.10)$ \\
\hline $\mathrm{BMI}\left(\mathrm{kg} / \mathrm{m}^{2}\right)$ & $23.88(4.83)$ \\
\hline Fat mass $(\mathrm{kg})$ & $20.02(8.74)$ \\
\hline Lean body mass $(\mathrm{kg})$ & $40.49(11.10)$ \\
\hline Bone mass $(\mathrm{kg})$ & $2.03(0.47)$ \\
\hline
\end{tabular}

Note: SD: standard deviation; BMI: body mass index; kg: kilogram; m: meter

categories, 3 of the 26 patients (11.5\%) were classified as underweight, 16 (61.5\%) as normal weight, and 7 (27\%) as overweight.

Table 3 shows the REE measured by IC and by the predictive equations. All equations underestimated the REE. In the adequacy analysis, a better accuracy (46.2\%) and smaller difference (127.4 kcal) were achieved with the WHO equation using weight and height ${ }^{17}$, as shown in Table 3. The two equations proposed by Cunningham ${ }^{20,21}$ showed the worst accuracy. The Bland and Altman's plots are presented in Figure 1.

\section{Discussion}

NF1 is a rare, unpredictable, and incurable disease where the patients and their families are faced with 
Table 3. Resting energy expenditure, difference, and adequacy between indirect calorimetry and predictive equations

\begin{tabular}{|c|c|c|c|c|c|c|c|c|c|}
\hline \multirow[b]{2}{*}{ Method } & \multicolumn{2}{|c|}{ REE (kcal/d) } & \multicolumn{2}{|c|}{ Difference (kcal/d) } & \multicolumn{5}{|c|}{ Adequacy of Predicted Resting Metabolic Rate } \\
\hline & Mean (SD) & $P$-value* & Median & $\mathrm{Cl} 95 \%$ & $\begin{array}{l}\text { Underestimat- } \\
\text { ed }<90 \%\end{array}$ & $\begin{array}{l}\text { Accurated } \\
90-110 \%\end{array}$ & $\begin{array}{c}\text { Overestimated } \\
>110 \%\end{array}$ & Median (\%) & $\mathrm{Cl} 95 \%$ \\
\hline Indirect calorimetry & $1633.91(471.14)$ & - & - & - & - & - & - & - & - \\
\hline Harris-Benedict (1919) & $1476.56(257.00)$ & 0.007 & 157.90 & $48.19-266.52$ & $50.0(n=13)$ & $38.5(n=10)$ & $11.5(n=3)$ & 89.27 & $85.10-105.72$ \\
\hline WHO (1985) (weight) & $1508.79(258.85)$ & 0.027 & 145.89 & $15.16-235.08$ & $50.0(n=13)$ & $38.5(n=10)$ & $11.5(n=3)$ & 91.18 & $87.15-107.67$ \\
\hline $\begin{array}{l}\text { WHO (1985) (weight } \\
\text { and height) }\end{array}$ & 1519.85 (271.09) & 1 041 & 127.38 & $5.14-222.98$ & $42.3(n=11)$ & $46.2(n=12)$ & $11.5(n=3)$ & 92.02 & $87.78-108.13$ \\
\hline Schofield (1985) & $1495.73(255.42)$ & 0.017 & 154.19 & $27.44-248.92$ & $50.0(n=13)$ & $38.5(n=10)$ & $11.5(n=3)$ & 90.38 & $86.41-106.74$ \\
\hline Henry \& Ress (1991) & $1379.11(232.81)$ & $<0.001$ & 259.11 & $141.15-368.46$ & $73.1(n=19)$ & $15.4(n=4)$ & $11.5(n=3)$ & 83.28 & $79.69-98.30$ \\
\hline Cunningham (1980) & 1390.79 (244.29) & $<0.001$ & 229.17 & $130.43-355.82$ & $80.8(n=21)$ & $11.5(n=3)$ & $7.7(n=2)$ & 86.24 & $80.27-99.00$ \\
\hline Cunningham (1991) & $1244.59(239.85)$ & $<0.001$ & 376.03 & $275.51-503.14$ & $88.5(n=23)$ & $7.7(n=2)$ & $3.8(n=1)$ & 76.94 & $71.79-87.93$ \\
\hline Mifflin-St.Jeor (1990) & 1388.49 (267.29) & $<0.001$ & 257.16 & $136.73-354.12$ & $73.1(n=19)$ & $19.2(n=5)$ & $7.7(n=2)$ & 84.61 & $79.88-98.39$ \\
\hline
\end{tabular}

Note: SD: standard deviation; REE: resting energy expenditure; CI95\%: 95\% confidence interval; *significance between indirect calorimetry and equations. Means were compared using paired student's t-test

uncertainty. However, some treatments, nutrition based and multidisciplinary, may ameliorate some clinical characteristics of the disease and contribute to improvements in the quality of life of these patients. Previous studies have shown that the clinical severity and social representations of NF1 are correlated with quality of life, as reported by NF1 patients and their families ${ }^{23,24,25}$.

In our study, the main objective was to find accessible and practical options for determining the energy requirement of NF1 patients, facilitating ambulatory patient care and understanding of energy expenditure in NF1. In the comparison of the REE values obtained by IC and by eight predictive equations, it was observed that all equations underestimated the energy requirement, so these equations should be used with caution. The equation proposed by the WHO including weight and height ${ }^{17}$ presented the smallest difference from in the REE obtained by IC and good accuracy and adequacy, but the difference between the values was statistically significant $(P=0.041)$, indicating that this equation should also be used with caution.

The two equations proposed by Cunningham ${ }^{20,21}$ had the worst accuracy, and used fat-free mass (FFM) only. As the proportion of FFM is low in NF1 individuals ${ }^{7,26,27}$, the use of these two equations is not adequate in this disease. All eight equations underestimated the REE in NF1 patients possibly because of the changes in energy metabolism due to this disease, as hypothesized by Souza et al. ${ }^{6}$. Recently, Souza et al. ${ }^{7}$ showed that individuals with NF1 presented increased REE (adjusted by weight, lean body mass, and appendicular lean body mass), as compared to controls matched by age, sex, BMI and physical activity level, which can explain the differences in REE observed in our study.

In the case of NF1 patients, these equations should be used carefully since they all underestimated the REE. The use of these equations can lead to inadequate energy consumption in this population, and long-term underfeeding can cause changes in body composition, such as reduced muscle mass and weight, and, consequently, metabolic and hormonal alterations ${ }^{28,29}$. NF1 patients usually have low weight, height, and lean body mass, as described in previous studies ${ }^{7,26,27,30}$. Although some nutritional studies on NF1 have been carried out recently, little is known about the impact of diet and nutrition on the clinical characteristics of the disease ${ }^{6,7,30}$. Thus, as previously mentioned, it is important to determine the most appropriate predictive equation for NF1 patients. Prolonged over or underfeeding can have adverse clinical effects, especially in the absence of adequate monitoring.

This study has some limitations, such as no stratification by sex due the sample size. Randomization would have improved the external validity of this study. Despite the limitations, this research has outlined the important clinical aspects to be considered when looking for alternatives that can enable health professionals monitor NF1 patients. Future research should involve validation studies of these equations or even propose new equations for this purpose.

\section{Conclusions}

This study showed that predictive REE equations should be used with caution, since most of the equations underestimated the energy requirement in the NF1 population. None of the commonly used equations to estimate REE were found to be suitable for the NF1 population in this study. IC is the preferred method to prevent over or underestimation of REE values. Nutritional interventions could be used when the energy needs of a population are known. In sum, energy metabolism must be well investigated in NF1 patients.

\section{Financial support}

The authors received financial support from three Brazilian government funding agencies: CAPES, National Council of Technological and Scientific Development CNPq (\#471725/2013-7) and FAPEMIG (\#APQ-00928-11; 

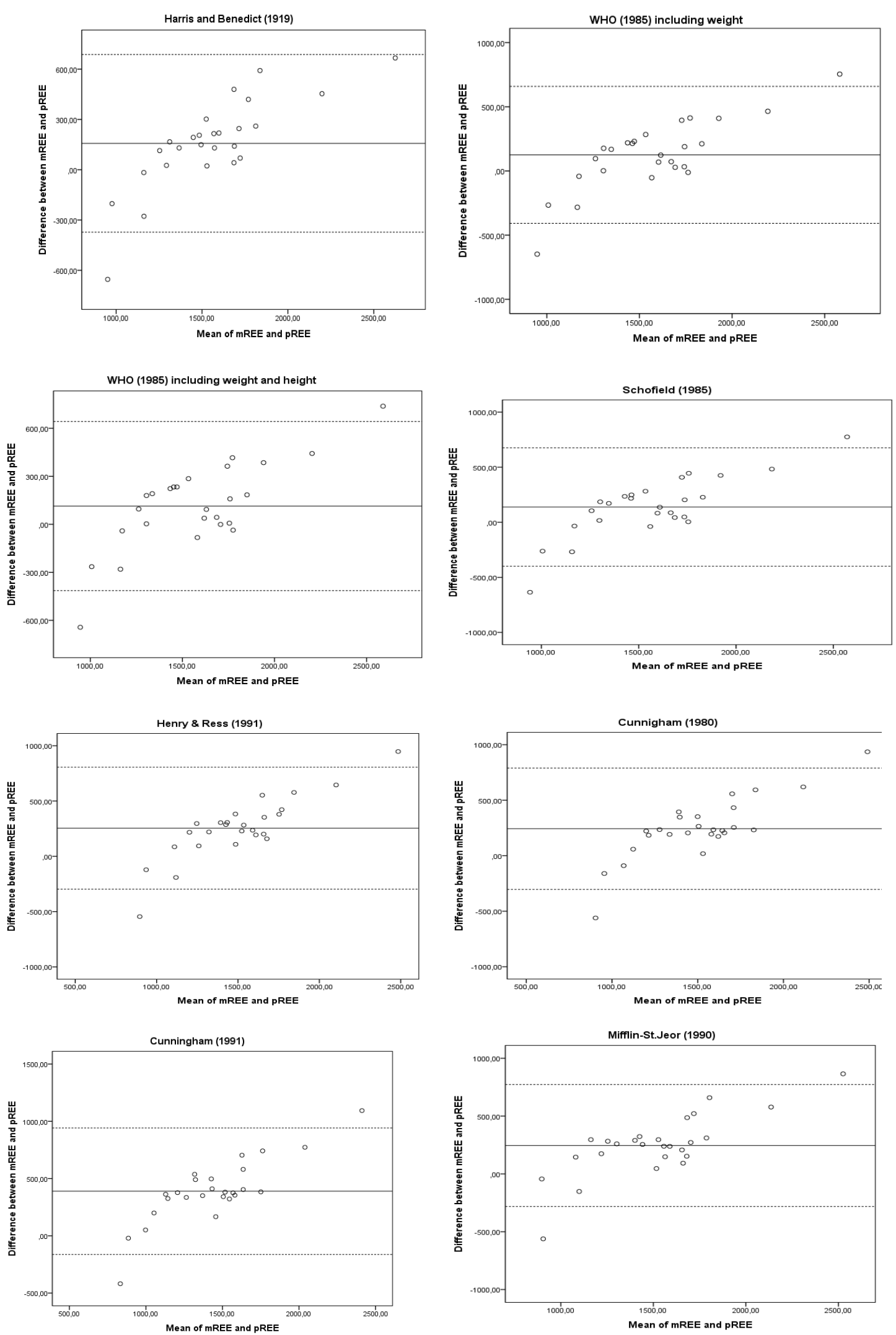

Note: REE: resting energy expenditure; mREE: measured resting energy expenditure evaluated by indirect calorimetry; pREE: predicted resting energy expenditure using predictive equations

Figure 1: Bland and Altman plots for comparison between REE from indirect calorimetry and predictive equations 
\#PPM-00120-14). The funding sources played no role in the design, analysis, writing, or decision to publish.

\section{Author Contributions}

All authors (MLRS, AKJ, LORC, DLVS, ASM, JFS e NAR) conceived, planned and performed the work leading to the report and interpreted the results. Also written, reviewed and approved the final version.

\section{References}

1. Rodrigues LO, Batista PB, Goloni-Bertollo EM, etal. Neurofibromatoses: part 1 - diagnosis and differential diagnosis. Arq Neuropsiquiatr 2014; 72(3): 241-250.

2. National Institutes of Health Consensus Development Conference Statement: neurofibromatosis. Bethesda Md, USA, July 13-15, 1987. Neurofibromatosis. 1988; 1(3): 172-178.

3. Souza JF, Toledo LL, Ferreira MCM, et al. Neurofibromatose Tipo 1 mais comum e mais grave do que se imagina. Rev Assoc Med Bras. 2009; 55(4): 394-9.

4. Riccardi VM. Neurofibromatosis type 1 is a disorder of dysplasia: the importance of distinguishing features, consequences and complications. Birth Defects Research. 2010; 88: 9-14.

5. Korf BR. Neurofibromatosis. Handb Clin Neurol. 2013; 111: 333-40.

6. Souza MLR, Jansen AK, Martins AS, et al. Nutrient intake in neurofibromatosis type 1: a cross-sectional study. Nutrition. 2015; 31(6): 858-862.

7. Souza MLR, Jansen AK, Rodrigues LOC, et al. Increased resting metabolism in neurofibromatosis type 1. Clinical Nutrition ESPEN. 2019; 32: 44-49.

8. Levine JA. Measurement of energy expenditure. Public Health Nutr. 2005; 8(7A): 1123-32.

9. Psota T, Chen KY. Measuring energy expenditure in clinical populations: rewards and challenges. Eur J Clin Nutr. 2013; 67(5): 436-442.

10. Oshima T, Berger MM, Waele E, et al. Indirect calorimetry in nutritional therapy. A position paper by the ICALIC study group. Clinical Nutrition. 2017; 36(3): 651-662.

11. WHO - World Health Organization. Physical status: the use and interpretation of anthropometry. Genebra, 1995. 452p. (Technical Report Series No. 854).

12. WHO - World Health Organization. Obesity - preventing and managing the global epidemic. Report of a WHO consultation on obesity. Genebra, 2000. 253p. (Technical Report Series, No.894).

13. Craig CL, Marshall AL, Sjostrom M, et al. International physical activity questionnaire: 12-country reliability and validity. Med Sci Sports Exerc. 2003; 35(8): 1381-1395.

14. Haugen HA, Chan LN, Li F. Indirect calorimetry: a practical guide for clinicians. Nutr Clin Pract. 2007; 22(4): 377-388.
15. Weir JVB. New methods for calculating metabolic rate with special reference to protein metabolism. J Physiol Lond. 1949; 109: 1-9.

16. Harris JA, Benedict FG. A biometric study of human basal metabolism. Proc Natl Acad Sci USA. 1919; 4(12): 370-373.

17. WHO - World Health Organization. Energy and protein requirements. Report of a joint FAO/WHO/UNU Expert Consultation. Genebra, 1985. 206p. (Technical Report Series, No.724).

18. Schofield WN. Predicting basal metabolic rate, new standards and review of previous work. Hum Nutr Clin Nutr. 1985; 39(Suppl1): 5-41.

19. Henry CJK, Rees DG. New predictive equations for the estimation of basal metabolic rate in tropical peoples. Eur J Clin Nutr. 1991; 45(4): 177-185.

20. Cunningham JJ. A reanalysis of the factors influencing basal metabolic rate in normal adults. Am J Clin Nutr. 1980; 33(11): 2372-2374.

21. Cunningham JJ. Body composition as a determinant of energy expenditure: a synthetic review and a proposed general prediction equation. Am J Clin Nutr. 1991; 54(6): 963-969.

22. Mifflin MD, St Jeor ST, Hill LA, et al. A new predictive equation for resting energy expenditure in healthy individuals. Am J Clin Nutr. 1990; 51(2): 241-247.

23. Draucker CB, Nutakki K, Varni JW, et al. The health-related quality of life of children, adolescents, and young adults with neurofibromatosis type 1 and their families: analysis of narratives. J Spec Pediatr Nurs. 2017; 22(2): e12174.

24. Cerelo AC, Gianordoli-Nascimento IF, Rezende NA. Neurofibromatose tipo 1: representações da doença para paciente e familiares. Ciência e Saúde Coletiva. 2013; 13: 18-26.

25. Sanagoo A, Jouybari L, Koohi F, et al. Evaluation of QoL in neurofibromatosis patients: a systematic review and meta-analysis study. BMC Neurol. 2019; 19: 123-135.

26. Stevenson D, Moyer-Mileur L, Carey J, Quick J, Hoff C, Viskochil D. Casecontrol study of the muscular compartments and osseous strength in neurofibromatosis type 1 using peripheral quantitative computed tomography. Journal of Musculoskeletal and Neuronal Interactions 2005; 5(2): 145-149.

27. Souza M, Jansen A, Martins A, Rodrigues L, Rezende N. Body composition in adults with neurofibromatosis type 1. Rev Assoc Med Bras 2016; 62(9): 831-836.

28. Thearle MS, Pannacciulli N, Bonfiglio S, Pacak K, Krakoff J. Extent and determinants of thermogenic responses to 24 hours of fasting, energy balance, and five different overfeeding diets in humans. J Clin Endocrinol Metab 2013; 98(7): 2791-2799.

29. Müller MJ, Bosy-Westphal A. Effect of over- and underfeeding on body composition and related metabolic functions in humans. Curr Diab Rep 2019; 19(11): 108-118.

30. Martins AS, Jansen AK, Rodrigues LOC, Matos CM, Souza MLR, Miranda DM et al. Increased insulin sensitivity in individuals with neurofibromatosis type 1 . Arch Endocrinol Metab 2018; 62(1): 4146. 